\title{
Positive Perfectionism: Seeking the Healthy "Should", or Should We?
}

\author{
Danielle M. Andrews', Lawrence R. Burns' ${ }^{1}$ Jacqueline K. Dueling2 \\ ${ }^{1}$ Department of Psychology, Grand Valley State University, Allendale, USA \\ ${ }^{2}$ Department of Psychology, Roosevelt University, Chicago, USA \\ Email: burnsl@gvsu.edu
}

Received May 2014

\begin{abstract}
Using a prospective design we examined the nomological network of positive and negative perfectionism by considering relations with optimism, pessimism, neuroticism, conscientiousness, and variables of health and psychological well-being. Positive perfectionism was found to have a large amount of variance in common with optimism and conscientiousness and negative perfectionism was found to share a large amount of variance with pessimism and neuroticism, but not enough to be considered redundant in either case. Importantly, both positive and negative perfectionism were found to add significant incremental validity to the prediction of the criterion measures even after controlling for the influence of time one variables. Implications of these findings for future research on perfectionism are discussed.
\end{abstract}

\section{Keywords}

Positive Perfection, Negative Perfection, Positive Affect, Negative Affect, Optimism, Pessimism, Health Behaviors, Psychological Well-Being

\section{Positive Perfection: Seeking the Healthy "Should" or Should We?}

The perfectionism construct has long been conceptualized as a pathological personality trait [1]-[3]. Reference [4] characterized perfectionists as likely to engage in distorted unhealthy "all or nothing" dichotomous thinkingespecially by using "should” statements (e.g., "I should have known better," "I should be a better person," etc.) that inevitably diminished their accomplishments and set them up for future failure. However, within the past few years, researchers have begun to investigate the idea that perfectionism can be beneficial to the individual rather than leading to some manifestation of psychopathology [5]-[8].

Perfectionism can be advantageous under certain circumstances. This is evident in individuals who motivate themselves to increase their performance in daily life activities and goal-oriented tasks. Perfectionism is not a mental disorder; rather, it is a set of beliefs about oneself and one's relation to others as in [9] and can be seen as more or less beneficial to an individual depending upon their manifestation of either positive or negative related perfectionistic qualities [10]. Positive perfectionism has been shown to improve performance on several types of neurocognitive tests, including working memory tasks, suggesting it is adaptive in nature [11]. Perfectionism has even been proposed to be a key element in the gifted personality [12] and [13]. 
In 1978, reference [14] described normal perfectionism, where the individual is able to set high goals and standards which act as motivators; when the situation changes, individuals have the ability to modify their previous standards. This normal type of perfectionism is seen as beneficial because it is adaptive and a sense of satisfaction is gained from accomplishments. Those who are seen to have a normal type of perfectionism have high personal standards and strive to accomplish achievements through positive consequences. Hamachek also described negative, or neurotic, perfectionism characterized by an individual being inflexible in goal attainment and overly critical of failure. A sense of self-doubt and a tendency to avoid negative consequences also accompanies negative perfectionism. With negative perfectionism, a sense of accomplishment is perceived as "unearned" because one perceives the level of achievement as hardly good enough. This conceptualization allows for some positive aspects of perfectionistic behavior, while at the same time, accounting for its negative characteristics. Other similarly dichotomous models use terms such as satisfied and dissatisfied perfectionism [15], adaptive and maladaptive perfectionism [16]-[18], positive striving and maladaptive evaluation and functional and dysfunctional perfectionism [19].

The Positive and Negative Perfectionism Scale or PNP [5] represents this alternative view of perfectionism, utilizing a behavioral perspective that is based, in part, on Hamachek's dichotomous conceptualization. From this perspective, perfectionism is determined to be either positive or negative based on the reinforcers that follow the perfectionistic behavior. Reference [20] states that perfectionistic behavior cannot be determined to be positive or negative without considering the relevant reinforcers. Reference [21] provides support for the behavioral approach, concluding that individuals are attuned to varying motivational sources as a function of their perfectionistic tendencies when considering perfectionism and achievement goals. The PNP has two subscales. Positive perfectionism is defined by the experience of positive reinforcement as a result of perfectionistic behavior and is similar to Hamachek's normal perfectionism. The second subscale is negative perfectionism (similar to Hamachek's neurotic perfectionism) which is a perfectionistic behavior motivated by a fear of failure or to avoid negative consequences.

References [5] and [12] note that few systematic studies of normal perfectionism have been conducted. One purpose of this study is to address this issue. Recent research on negative perfectionism has been consistent with previous research findings based on pathology-based models, but the findings with positive perfectionism, although generally supportive of its validity have been less demonstrative of its utility (see also [22] [23]). One possible explanation for these findings may lie in the fact that, as assessed by the PNP, perfectionism is conceptualized by positive and negative outcome expectancies [24]. The two subscales of the PNP model are quite similar in nature to the broadly defined outcome expectancies of optimism and pessimism. So much so, that it is difficult to see how they might be unrelated [25]. Just how these might be different from the similar, albeit more broadly defined outcome expectancies of optimism and pessimism is not clear [25]. For example, in an extensive series of studies [26] reported on the positive effects of optimism and the negative effects of perfectionism as moderators of health outcomes. Based on these findings we hypothesize negative perfectionism as consistent with prior findings, but the relationship and overlap between positive perfectionism, optimism, and health behaviors warrants further investigation.

Reference [27] used the Perfectionism Inventory, which is shown to include two primary factors: conscientious perfectionism and self-evaluative perfectionism [28]. Conscientious perfectionism appears similar to positive perfectionism as it includes organization, striving for excellence, planfulness and high standards of others [28]. Self-evaluative perfectionism seems to encompass the more negative facets of perfectionism as it includes concern over mistakes, need for approval, rumination and perceived parental pressure [28]. Reference [27] found a strong positive relation between conscientious perfectionism and the personality trait, conscientiousness, and a small relation between conscientious perfectionism and neuroticism. This study contributed to the growing concerns of the validity of perfectionism and conscientiousness as separate entities. Reference [27] also reported a moderate relation between self-evaluative perfectionism and neuroticism suggesting some conceptual overlap; further complicating the distinctions between perfectionism and neuroticism. In a sample of Turkish university students, [17] found that adaptive perfectionism was significantly predicted by conscientiousness, openness, and extraversion while maladaptive perfectionism was significantly predicted by neuroticism, anxiety, and attachment avoidance. Conscientiousness was found to be the greatest predictor of adaptive perfectionism, compared to the other Big Five personality traits and attachment styles [17].

Subjective well-being is an important measure of psychological adjustment [29] and [30]. Reference [22] found a positive relation between subjective well-being (SWB), as measured by the Extended Satisfaction with Life 
Scale [31] and positive perfectionism. They also found a negative relationship between SWB and negative perfectionism [22]. Similarly, [32] reported a positive association between SWB and optimism and a negative relationship between SWB and pessimism. Given the apparent similarities in the associations between these constructs, further evaluation of how negative perfectionism may differ from pessimism is warranted.

In the current study, we attempt to further clarify the perfectionism construct as defined by [5] by examining the discriminant validity and utility of positive as well as negative perfectionism in predicting psychological well-being, in particular, depressive symptoms, anxiety, and health behaviors. These are important indicators of adjustment in a college student population, from which the participants will be drawn (see [33]). The second objective is to investigate the discriminant validity and utility of positive and negative perfectionism when positive and negative affectivity are controlled. Perfectionism, as conceptualized, appears to be related to a variety of other personality characteristics. Because of established relations between each of these constructs, the possibility of overlap with more global constructs of positive and negative affectivity [34] and with optimism and pessimism [25], the utility of perfectionism warrants further consideration. Therefore, it is important to determine whether associations between positive and negative perfectionism and the criterion measures of well-being are a reflection of shared variance between perfectionism and the measures of affectivity, optimism and pessimism.

There remains little agreement on the precise definition and appropriate measures of perfectionism, although two distinct factors are found to lie within perfectionism consistently using factor analysis [35]. The goal of the present study is to further parse out the differences between the two types of perfectionism, positive and negative perfectionism, using the behavioral model and Positive and Negative Perfectionism Scale. The present study seeks to address the current ambiguity of research surrounding perfectionism with two main goals. First, the current study aims to support the validity and utility of positive and negative perfectionism as separate entities. Secondly, we sought to investigate the difference of positive perfectionism from optimism and positive affectivity as well as the difference of negative perfectionism from neuroticism and pessimism.

\section{Method}

\subsection{Participants}

The participants in our sample were 188 undergraduates (91 women, 97 men) enrolled in an introductory psychology course at a Midwestern university. Participants completed all measures in exchange for extra credit received in the course. The sample had mean age of 19.0 ( $\underline{\mathrm{SD}}=3.1)$ years. The ethnic/racial composition was $90 \%$ Caucasian, 6\% African-American, 2\% Asian and 2\% other. Three participants did not complete all measures. Their data was excluded. Final sample size was 185.

\subsection{Procedure}

Informed consent was obtained. The study measures were completed in two small group-testing sessions held during a single semester. In the first session, the following tests were administered; the Positive and Negative Perfectionism Scale (PNP), the Positive and Negative Affect Schedule (PANAS), and the Extended Life Orientation Test (ELOT). Participants then self-addressed an envelope to their local address and approximately five weeks later the Behavioral Inhibition and Activation Scale (BIS), and the Wellness Inventory of the Lifestyle Assessment Questionnaire were mailed to them. All materials were returned in person directly to the lab. To assure confidentiality, only subject numbers were placed on the answer sheets. There were no observed effects from the different session environments. All subjects were debriefed after they completed all measures.

\subsection{Measures}

\subsubsection{Positive and Negative Perfectionism Scale (PNP)}

This scale assesses perfectionism from a functional or behaviorist perspective. There are two subscales that represent the different types of rein forcers a person could experience. Accordingly, positive perfectionism is believed to be a type of perfectionism resulting from linking positive reinforcements with antecedent perfectionistic behaviors. Negative perfectionism is theorized to be directly linked to negative reinforcements. The PNP [5] consists of 40 Likert scale questions with responses ranging from strongly disagree (1), to strongly agree (5). Scores were obtained by summing the coded set of 18 questions representing positive perfectionism and 22 questions depicting negative perfectionism. 


\subsubsection{The Positive and Negative Affect Schedule (PANAS)}

The PANAS [34] is a 20 item, Likert-type instrument that consists of a 10-item Positive Affect scale and a 10-item Negative Affect scale. The present study used the "trait" rather than "state" instructions; that is, participants were asked to report how they generally feel. Positive affect questions assess to what extent the participant is attentive, interested, alert, excited, enthusiastic, inspired, proud, determined, strong and active. Negative affect questions assess to what extent the participant is distressed, upset, hostile, irritable, scared, afraid, ashamed, guilty, nervous, and jittery. In the experiment, the alphas were 0.82 and 0.86 for Positive Affectivity and Negative Affectivity respectively. Support for the convergent and discriminant validity of the PANAS has been reported.

\subsubsection{Extended Life Orientation Test (ELOT)}

The ELOT [36] is a 20-item bidimensional measure of optimism and pessimism consisting of a six item Optimism scale and a nine item Pessimism scale. The remaining five items are filler items. The ELOT is based on a factor analysis of a pool of items from the Life Orientation Test (LOT; [25]) and the Optimism and Pessimism Scale (OPS; [37]. Alphas were reported as 0.77 and 0.89 and test-retest as 0.73 and 0.84 for optimism and pessimism respectively.

\subsubsection{The NEO Five Factor Inventory: Form S (NEO-FFI)}

The NEO-FFI [38] is a 60-item short form version of the NEO Personality Inventory. It consists of 12 items each for the 5 factors: Neuroticism (N), Extraversion (E), Openness (O), Agreeableness (A) and Conscientiousness (C). We used the neuroticism scale. Participants were asked to mark each item on a 5-point scale (strongly disagree to strongly agree) according to how well it described them. Reliability and validity are well established.

\subsubsection{The Behavioral Inhibition and Activation Scale (BIS/BAS)}

Behavioral Inhibition System/Behavioral Activation System (BIS/BAS; [39]).

To assess for BIS/BAS motives, we used the BIS/BAS scales. The BIS/BAS scales are a 20-item: four-point Likert-type measure of BIS/BAS motives composed of four subscales. Respondents are asked to rate the extent of their agreement from 1 (strongly disagree) to 4 (strongly agree). The BIS scale is a self-report measure used to assess one's effort required to regulate aversive motives, in which the desired goal is to move away or avoid something unpleasant. This questionnaire has a series of statements in which participants can either agree or disagree with. It asks the participant to respond to what degree they either agree or disagree with a statement and it ranges from 1: "very true for me" to 4: "very false for me" [39].

\subsubsection{Health Practices}

Health practices were assessed by the Wellness Inventory of the Lifestyles Assessment Questionnaire [40] and [41]. Composed of 10 subscales the inventory is designed to assess student's current levels of wellness. Internal consistencies in the validation study were reported as ranging from 0.69 to 0.94 and test retest values were reported as ranging from 0.81 to 0.97 . For this study we retained all scales with alphas above 0.70 [42]. The physical exercise subscale measures one's commitment to maintain physical fitness (e.g., "I participated in strenuous sports"). The social-environmental subscale measures the degree to which one interacts with others (e.g., "I went out of my way to help others"). The emotional awareness and acceptance subscale measures the degree to which one has an awareness and acceptance of one's feelings and related behaviors (e.g., "I talked with friends about my thoughts and feelings"). The last scale used was the occupational subscale, which measures the satisfaction gained from one's work (e.g., "I found satisfaction from the work I did").

\section{Results}

As shown in Table 1, positive perfectionism was significantly positively correlated with optimism and positive affect, while significantly negatively correlated with pessimism and neuroticism. On the other hand, negative perfectionism was significantly positively correlated with pessimism and neuroticism, while significantly negatively correlated with optimism and positive affect (Table 1).

In order to determine how much of the variance in positive perfectionism is accounted for by optimism and positive affectivity combined, and the amount of variance in negative perfectionism is accounted for by pessimism and neuroticism combined, the authors performed separate hierarchical regression analyses on each measure of 
perfectionism consisting of two steps. Optimism or pessimism was entered as the first step in the analysis followed by positive affectivity or neuroticism as the second step. The results of these analyses are shown in Table 2.

All zero-order correlations, means, standard deviations, and Cronbach's alphas are reported in Table $\mathbf{1 .}$

Optimism and positive affectivity were found to account for approximately $13.4 \%$ of the variance in the positive perfectionism scale. Pessimism and neuroticism combined were found to account for about $43.7 \%$ of the variance in the negative perfectionism scale.

In the next set of analyses, the authors appraised the contribution of each perfectionism measure to the prediction of measures of health and psychological well-being by computing Pearson partial correlations, controlling for optimism or positive affectivity when the predictor was positive perfectionism, and controlling for pessimism or neuroticism when the predictor was negative perfectionism. The results for positive perfectionism are shown in Table 3, and those for negative perfectionism are shown in Table 4.

In relation to measures of health and well-being, positive perfectionism was found to have small positive correlations with physical exercise, sociality, emotional awareness and acceptance, positive affect, joviality affect, negative affect, fear, and scores on the behavioral-inhibition scale (Table 3). Positive perfectionism had a moderate positive correlation with occupational factors (Table 3). The correlations between positive perfectionism and physical exercise, sociality, emotional awareness and acceptance, occupational factors, positive affect, and joviality affect became smaller when controlling for either optimism or positive affect. Inversely, the correlations between positive perfectionism and state anxiety, negative affect, fear, and scores on the behavioral-inhibition scale became greater as either optimism or positive affect was controlled for.

Negative perfectionism was found to have small negative correlations with physical exercise, emotional awareness and acceptance, joviality affect, and scores on the behavioral-activation fun seeking scale (Table 4). Negative perfectionism was shown to have a moderate negative correlation with state anxiety (Table 4). Negative perfectionism was also found to have a moderate positive relationship with negative affect, fear, hostility, sadness, and scores on the behavioral-inhibition scale (Table 4). All of the aforementioned variables of health and well-being had smaller correlations with negative perfectionism when either pessimism or neuroticism was controlled for.

Table 1. Zero-order correlations, cronbach alphas, means, and standard deviations among the major study variables.

\begin{tabular}{lccccccc}
\hline & Variable & 1 & 2 & 3 & 4 & 5 & 6 \\
\hline 1 & Positive Perfectionism & $(0.89)$ & - & - & - & - & - \\
2 & Negative Perfectionism & 0.08 & $(0.85)$ & - & - & - & - \\
3 & Optimism & 0.17 & -0.36 & $(0.78)$ & - & - & - \\
4 & Pessimism & -0.16 & 0.55 & -0.68 & $(0.89)$ & - & - \\
5 & Positive Affect & 0.36 & -0.19 & 0.45 & -0.50 & $(0.85)$ & - \\
6 & Neuroticism & -0.06 & 0.64 & -0.56 & 0.67 & -0.41 & $(0.87)$ \\
& Mean & 69.1 & 59.7 & 21.8 & 21.3 & 35.9 & 23.5 \\
& SD & 9.3 & 11.5 & 3.7 & 6.6 & 5.5 & 8.9 \\
\hline
\end{tabular}

Note: $N=185 ; r>.20, p<.001 ; r=0.19, p<0.01 ; r>0.10 \&<0.19, p<0.05$; Alphas on the diagonal.

Table 2. Hierarchical regression analysis showing amount of variance in positive perfectionism and negative perfectionism accounted for by optimism and positive affectivity or pessimism and neuroticism.

\begin{tabular}{|c|c|c|c|c|}
\hline \multirow[b]{2}{*}{ Predictor } & \multicolumn{2}{|c|}{ Positive Perfectionism } & \multicolumn{2}{|c|}{ Negative Perfectionism } \\
\hline & $\Delta \mathrm{R}^{2}$ & $\mathrm{~F}$ & $\Delta \mathrm{R}^{2}$ & $\mathrm{~F}$ \\
\hline Model 1 & - & - & - & - \\
\hline 1. Optimism & 0.031 & $5.77^{*}$ & - & - \\
\hline 2. Positive Affectivity & 0.103 & $21.45^{* *}$ & - & - \\
\hline Model 2 & - & - & - & - \\
\hline 1. Pessimism & - & - & 0.312 & $81.97^{* *}$ \\
\hline 2. Neuroticism & - & - & 0.125 & $40.12^{* *}$ \\
\hline
\end{tabular}

Note: $N=183 ;{ }^{*} \mathrm{p}<0.05,{ }^{* *} \mathrm{p}<0.01$. 
Table 3. Relations between positive perfectionism and measures of health and psychological well-being with and without optimism and positive affectivity controlled.

\begin{tabular}{cccc}
\hline & $\begin{array}{c}\text { Simple } \\
\mathrm{r}\end{array}$ & $\begin{array}{c}\text { Controlling } \\
\text { for OPT }\end{array}$ & $\begin{array}{c}\text { Controlling } \\
\text { for PA }\end{array}$ \\
\hline $\begin{array}{c}\text { Health and Psych. Well-being } \\
\text { Physical Exercise } \\
\text { Social }\end{array}$ & 0.168 & & 0.134 \\
Emotional Aware/Accept & 0.198 & 0.174 & 0.095 \\
Occupational & 0.252 & 0.201 & 0.070 \\
Positive Affect & 0.322 & 0.293 & -0.231 \\
State Anxiety & 0.205 & 0.157 & 0.112 \\
Joviality Affect & -0.027 & 0.065 & -0.070 \\
Negative Affect & 0.112 & 0.069 & 0.182 \\
Fear Affect & 0.123 & 0.175 & 0.156 \\
Hostility & 0.126 & 0.161 & 0.009 \\
Sadness & -0.040 & -0.012 & 0.012 \\
Beh-Inhibition & -0.062 & -0.023 & 0.164 \\
Beh-Act. Fun Seeking & 0.111 & 0.115 & -0.084 \\
\hline
\end{tabular}

Note: $N=185$. OPT = Optimism; PA = Positive Affect. $r>0.25, p<.001 ; r>0.18 \&<0.25, p<0.05 ; r<0.18 \&>0.14, p<0.05$.

Table 4. Relations between negative perfectionism and measures of health and psychological well-being with and without pessimism and neuroticism controlled.

\begin{tabular}{cccc}
\hline & $\begin{array}{c}\text { Simple } \\
\mathrm{r}\end{array}$ & $\begin{array}{c}\text { Controlling } \\
\text { for PES }\end{array}$ & $\begin{array}{c}\text { Controlling } \\
\text { for NEU }\end{array}$ \\
\hline Health and Psych. Well-being & & & 0.041 \\
Physical Exercise & -0.138 & -0.011 & -0.054 \\
Social & -0.040 & 0.080 & -0.083 \\
Emotional Aware/Accept & -0.291 & -.096 & 0.100 \\
Occupational & -0.026 & 0.099 & 0.057 \\
Positive Affect & -0.099 & 0.087 & 0.126 \\
State Anxiety & 0.108 & 0.100 & -0.080 \\
Joviality Affect & -0.228 & -0.068 & 0.106 \\
Negative Affect & 0.379 & 0.214 & 0.117 \\
Fear Affect & 0.322 & 0.197 & 0.112 \\
Hostility & 0.313 & 0.181 & 0.167 \\
Sadness & 0.370 & 0.222 & 0.322 \\
Beh-Inhibition & 0.491 & 0.458 & 0.007 \\
\hline Beh-Act. Fun Seeking & -0.185 & 0.027 & \\
\hline
\end{tabular}

Note: $N=185$. PES = Pessimism; NEU = Neuroticism. $r>025, p<0.001 ; r>0.18 \&<0.25, p<0.01 ; r<0.18 \&>0.14, p<0.05$.

In addition to these partial correlations, the tables also show the simple correlations between the perfectionism scales and the criterion measures before partialing out the variance associated with optimism, pessimism, positive affectivity, and neuroticism.

\section{Conclusions}

Using a prospective design we were able to determine that even controlling for results gathered at time one, positive and negative perfectionism still added significant incremental validity to measures of health and subjective well-being. Research has shown that positive and negative perfectionism can predict changes related to mental health criteria, including psychological well-being and distress. This is very important for future research, highlighting the utility of using positive and negative perfectionism in predicting future life satisfaction and psy- 
chological health.

Positive perfectionism may act as a buffer against psychological distress given its corresponding lower levels of anxiety than those reported by negative perfectionists and non-perfectionists. It is our opinion that positive perfectionists view potentially anxiety-provoking situations with significantly less self-criticism and focus on future improvements. The relationship between positive perfectionism and increased subjective well-being may be a result of better coping strategies, greater optimism, fewer depressive symptoms, less psychological distress, greater self-esteem, feelings of pride and/or greater academic success. Further research is required to better understand the mediators between positive perfectionism and subjective well-being.

In conclusion, our findings suggest that, for some, positive perfectionism and pursuit of the healthy "should" may prove beneficial and deserving of any rewards accrued.

\section{References}

[1] Pacht, A.R. (1984) Reflections on Perfectionism. American Psychologist, 39, 386-390. http://dx.doi.org/10.1037/0003-066X.39.4.386

[2] Frost, R.O., Marten, P., Lahart, C. and Rosenblate, R. (1990) The Dimensions of Perfectionism. Cognitive Therapy and Research, 14, 449-468. http://dx.doi.org/10.1007/BF01172967

[3] Hewitt, P.L. and Flett, G.L. (1991) Perfectionism in the Self and Social Contexts: Conceptualization, Assessment and Association with Psychopathology. Journal of Personality and Social Psychology, 60, 456-470.

http://dx.doi.org/10.1037/0022-3514.60.3.456

[4] Burns, D.D. (1980, November) The Perfectionist’s Script for Self-defeat. Psychology Today, 34-51.

[5] Terry-Short, L.A, Owens, R.G., Slade, P.D. and Dewey, M.E. (1995) Positive and Negative Perfectionism. Personality and Individual Differences, 18, 663-668. http://dx.doi.org/10.1016/0191-8869(94)00192-U

[6] Norman, R.M.G., Davies, R., Nicholoson, I.R., Cortese, L. and Malla, A.K. (1998) The Relationship of Two Aspects of Perfectionism with Symptoms in a Psychiatric Outpatient Population. Journal of Social and Clinical Psychology, 17, 50-68. http://dx.doi.org/10.1521/jscp.1998.17.1.50

[7] Rhéaume, J., Freeston, M.H., Ladouceur, R., Bouchard, C., Gallant, L., Talbot, F. and Vallières, A. (2000) Functional and Dysfunctional Perfectionists: Are They Different on Compulsive-like Behaviors? Behaviour Research and Therapy, 38, 119-128. http://dx.doi.org/10.1016/S0005-7967(98)00203-4

[8] Slaney, R.B., Rice, K.G. and Ashby, J.S. (2002) A Programmatic Approach to Measuring Perfectionism: The Almost Perfect Scales. In: Flett, G.L. and Hewitt, P.L., Eds., Perfectionism: Theory, Research, and Treatment, American Psychological Association, Washington DC, Chapter 3, 63-88. http://dx.doi.org/10.1037/10458-003

[9] Greenspon, T.S. (2000) “Healthy Perfectionism” Is an Oxymoron! The Journal of Secondary Gifted Education, 4, 197208.

[10] Slade, P.D. and Owens, R. (1998) A Dual Process Model of Perfectionism Based on Reinforcement Theory. Behavior Modification, 22, 372-390. http://dx.doi.org/10.1177/01454455980223010

[11] Slade, P.D., Coppel, D.B. and Townes, B.D. (2009) Neurocognitive Correlates of Positive and Negative Perfectionism. International Journal of Neuroscience, 119, 1741-1754. http://dx.doi.org/10.1080/00207450902915212

[12] Parker, W.D. and Adkins, K.K. (1995) A Psychometric Examination of the Multidimensional Perfectionism Scale. Journal of Psychopathology and Behavioral Assessment, 17, 323-334. http://dx.doi.org/10.1007/BF02229054

[13] Orange, C. (1997) Gifted Students and Perfectionism. Roeper Review, 20, 39-43. http://dx.doi.org/10.1080/02783199709553849

[14] Hamachek, D.E. (1978) Psychodynamics of Normal and Neurotic Perfectionism. Psychology, 15, 27-33.

[15] Slade, P.D., Newton, T., Butler, N.M. and Murphy, P. (1991) An Experimental Analysis of Perfectionism and Dissatisfaction. British Journal of Clinical Psychology, 30, 169-176. http://dx.doi.org/10.1111/j.2044-8260.1991.tb00932.x

[16] Black, J. and Reynolds, W.M. (2013) Examining the Relationship of Perfectionism, Depression, and Optimism: Testing for Mediation or Moderation. Personality and Individual Differences, 54, 426-431. http://dx.doi.org/10.1016/j.paid.2012.10.012

[17] Ulu, I.P. and Tezer, E. (2010) Adaptive and Maladaptive Perfectionism, Adult Attachment, and the Big Five Personality Traits. The Journal of Psychology, 144, 327-340. http://dx.doi.org/10.1080/00223981003784032

[18] Wang, K.T., Slaney, R.B. and Rice, K.G. (2007) Perfectionism in Chinese University Students from Taiwan: A Study of Psychological Well-Being and Achievement Motivation. Personality and Individual Differences, 42, 1279-1290. http://dx.doi.org/10.1016/j.paid.2006.10.006 
[19] Papadomarkaki, E. and Portinou, S. (2012) Clinical Perfectionism and Cognitive Behavioral Therapy. Psychiatrike, 23, 61-71.

[20] Owens, R.G. and Slade, P.D. (2008) So Perfect It’s Positively Harmful? Reflections on the Adaptiveness and Maladaptiveness of Positive and Negative Perfectionism. Behavior Modification, 32, 928-937. http://dx.doi.org/10.1177/0145445508319667

[21] Hanchon, T.A. (2010) The Relations between Perfectionism and Achievement Goals. Personality and Individual Differences, 49, 885-890. http://dx.doi.org/10.1016/j.paid.2010.07.023

[22] Mitchelson, J.K. and Burns, L.R. (1998) Career Mothers and Perfectionism: Stress at Work and at Home. Personality and Individual Differences, 25, 477-485. http://dx.doi.org/10.1016/S0191-8869(98)00069-5

[23] Burns, L.R., Dittmann, K.L., Nguyen, N.L. and Mitchelson, J.K. (2000) Academic Procrastination, Perfectionism, and Control: Associations with Vigilant and Avoidant Coping. Journal of Social Behavior and Personality, 15, 35-46.

[24] Flett, G., Hewitt, P., Blankenstein, K. and Koledin, S. (1991) Dimensions of Perfectionism and Irrational Thinking. Journal of Rational-Emotive and Cognitive Behavior Therapy, 9, 185-201. http://dx.doi.org/10.1007/BF01061229

[25] Scheier, M.E. and Carver, C.S. (1985) Optimism, Coping, and Health: Assessment and Implications of Generalized Outcome Expectancies. Health Psychology, 4, 219-247. http://dx.doi.org/10.1037/0278-6133.4.3.219

[26] Fry, P.S. (1994) Perfectionism, Humor, and Optimism as Moderators of Health Outcomes and Determinants of Coping Styles of Women Executives. Genetic, Social, and General Psychology Monographs, 121, 211-245.

[27] Cruce, S.E., Pashak, T.J., Handal, P.J., Munz, D.C. and Gfeller, J.D. (2012) Conscientious Perfectionism, Self-Evaluative Perfectionism, and the Five-Factor Model of Personality Traits. Personality and Individual Differences, 53, 268-273. http://dx.doi.org/10.1016/j.paid.2012.03.013

[28] Hill, R.W., Huelsman, T.J., Furr, M., Kibler, J., Vincente, B.B. and Kennedy, C. (2004) A New Measure of Perfectionism: The Perfectionism Inventory. Journal of Personality Assessment, 82, 80-91. http://dx.doi.org/10.1207/s15327752jpa8201_13

[29] Diener, E., Emmons, R.A., Larsen, R.J. and Griffin, S. (1985) The Satisfaction with Life Scale. Journal of Personality Assessment, 49, 71-75. http://dx.doi.org/10.1207/s15327752jpa4901_13

[30] Diener, E., Suh, E.M., Lucas, R.E. and Smith, H. (1999) Subjective Well-Being: Three Decades of Progress. Psychological Bulletin, 125, 276-302. http://dx.doi.org/10.1037/0033-2909.125.2.276

[31] Allison, D.B., Alfonso, V.C. and Dunn, G.M. (1991) The Extended Satisfaction with Life Scale. The Behavioral Therapist, 5, 15-16.

[32] Chang, E.C., D’Zurilla, T.J. and Maydeu-Olivares, A. (1997) Optimism and Pessimism as Partially Independent Constructs: Relationship to Positive and Negative Affectivity and Psychological Well-Being. Personality and Individual Differences, 23, 433-440. http://dx.doi.org/10.1016/S0191-8869(97)80009-8

[33] Weidner, G., Kohlman, C.-W., Dotzauer, E. and Burns, L.R. (1996) The Effects of Academic Stress on Health Behaviors in Young Adults. Anxiety, Stress, and Coping, 9, 123-133.

[34] Watson, D., Clark, L.A. and Tellegen, A. (1988) Development and Validation of Brief Measures of Positive and Negative Affect: The PANAS Scales. Journal of Personality and Social Psychology, 54, 1063-1070. http://dx.doi.org/10.1037/0022-3514.54.6.1063

[35] Stoeber, J. and Otto, K. (2006) Positive Conceptions of Perfectionism: Approaches, Evidence, Challenges. Personality and Social Psychology Review, 10, 295-319. http://dx.doi.org/10.1207/s15327957pspr1004_2

[36] Chang, E.C., D’Zurilla, T.J. and Maydeu-Olivares, A. (1994) Assessing the Dimensionality of Optimism and Pessimism Using a Multimeasure Approach. Cognitive Therapy and Research, 18, 143-160. http://dx.doi.org/10.1007/BF02357221

[37] Dember, W.N., Martin, S., Hummer, M.K., Howe, S. and Melton, R. (1989) The Measurement of Optimism and Pessimism. Current Psychology: Research and Reviews, 8, 102-119. http://dx.doi.org/10.1007/BF02686675

[38] Costa Jr., P.T. and McCrae, R.R. (1992) Revised NEO Personality Inventory (NEO PI-R) and NEO Five-factor Inventory (NEO-FFI) Professional Manual. Psychological Assessment Resources, Odessa, FL.

[39] Carver, C.S. and White, T.L. (1994) Behavioral Inhibition, Behavioral Activation, and Affective Responses to Impending Reward and Punishment: The BIS/BAS Scales. Journal of Personality and Social Psychology, 67, 319-333. http://dx.doi.org/10.1037/0022-3514.67.2.319

[40] Hettler, B. (1982) Wellness Promotion and Risk Reduction on a University Campus. In: Faber, M. and Reinhardt, A., Eds., Promoting Health through Risk Reduction, Macmillan, New York, 207-238.

[41] Richter, J.M. (1988) Reliability and Validity of the Lifestyles Assessment Questionnaire. In: Waltz, C.F. and Strickland, D.L., Eds., Measurement of Nursing Outcomes, Springer, New York, 352-376.

[42] Nunnally, J.C. (1978) Psychometric Theory. 2nd Edition, McGraw-Hill, Toronto. 